\title{
NAS issues mixed message on unintended effects of GM food
}

A report released on July 28 by a 13 -member committee of the Institute of Medicine within the National Academy of Sciences (NAS) in Washington, DC, proposes to extend voluntary testing to all new foods that have been modified, regardless of the technique used to create the modification. Although encouraging on the narrow, genetically modified (GM) food front, the report reveals a shift of attitude that could yet prove expensive for agbiotech companies, particularly if the report's recommended expansive regulatory and data-gathering practices were made mandatory.

The NAS report, "Safety of Genetically Engineered Foods: Approaches to Assessing Unintended Health Effects," was commissioned jointly by the Food and Drug Administration (FDA), the US Department of Agriculture (USDA), and the Environmental Protection Agency (EPA), all of which share responsibilities for regulating GM organisms and foods derived from them. This commission is part of the response by the agencies to a NAS report published four years ago that called on them "to better coordinate their work and to expand public access to the regulatory process" in this arena (Nat. Biotechnol. 18, 486, 2000).

Adverse health effects from consuming GM foods "have not been documented in the human population, but the technique is new and concerns about its safety remain," according to the report, which also notes that "even traditional methods such as cross-breeding can cause unexpected changes." Thus, the NAS committee recommends extending voluntary testing from new types of GM foods to testing foods that are developed by traditional breeding such as hybridization.

To assist in the process, the report urges industry and regulatory officials to build and to integrate databases that would include food sources that are subject to conventional breeding and newer cloning methods, instead of limiting special scrutiny to GM food sources alone, as federal agencies have been doing for more than a decade. NAS committee member and former FDA official Sanford Miller, now of the Polytechnic Institute and State University in Alexandria, Virginia, says: "We fully recognize that this is very expensive, but there are a lot of reasons for using public and private funds to set up a central depository of information.'
Until now, companies have been carrying out voluntary and proprietary testing-focusing on compositional changes rather than health testing-of GM crops that mostly are used in feed rather than in foods for humans. Although the report stands as a "guide for federal agencies to select the route of safety assessment," it does not fully specify what compositional changes would trigger such tests. Nor does it spell out how to improve epidemiological and survey tools to detect any "changes in the population's health that may be caused by these foods."

Instead, that challenge is left "to the agencies and industry," noting that they stand to benefit from using those tools to pick up what committee member Lynn Goldman of the Johns Hopkins University School of Public Health in Baltimore, $\mathrm{MD}$, and a former EPA official refers to as "truly unanticipated consequences."

Immediate reactions to the NAS report are proving it to be delphic. For instance, Michael Phillips, vice president of agricultural science and regulatory policy of the Biotechnology Industry Organization (BIO) in Washington, DC, cites the report as another "milestone in consumer acceptance of agricultural biotechnology." Thus, it "should lay to rest the few naysayers who continue to question the safety of these crops."

Perhaps not. For example, biotech critic Doug Gurian-Sherman, senior scientist at the Center for Food Safety, an activist think tank, in Washington, views the report as renewing warnings about "potentially harmful GM foods that we don't know much about." Furthermore, he says, "there are substantial gaps in our ability to identify unintended changes in biotech foods or to determine the human health impacts of those changes, and we need much more rigorous pre-market testing and post-market surveillance."

Gurian-Sherman and others continue to call for a mandatory pre-market approval process for GM foods as well as mandatory labeling, like in the European Union. To reach this end, Democratic Senator Richard Durbin of Illinois introduced legislation (S.2546) on June 17 that seeks to establish a mandatory approval process for such foods. However, the report, stops well short of recommending mandatory assessments, while potentially greatly expanding the scope of testing which is now done strictly on a voluntary basis by product sponsors. And the NAS committee leaves decisions about what foodstuffs would be reviewed to federal officials. For each case, officials and company representatives are "to determine whether and how much further evaluation is needed," explains NAS committee chair Bettie Sue Masters, a chemist from the University of Texas Health Science Center in San Antonio.

The NAS committee also urges the FDA, USDA and EPA to improve their ability to detect consumer trends in purchasing GM foods and to enable the traceability of such foods. "What they're asking for seems to be excessive. They don't give recommendations on how this would be done or who pays for it," says Lisa Dry of BIO. "And in balance with no apparent risk, it seems unnecessary."

Jeffrey L. Fox, Washington, DC 